\title{
A student's perspective from the Medical University of Innsbruck
}

\author{
U. Neubauer, G. Kastl
}

Innsbruck is known for its skiing resorts, the 'olden Dacherl'(golden roof) and the medical school, which recently has become a refuge for foreign students desperately seeking admission to medical education. However, the Medical University of Innsbruck is much more than a place of last resort for students; it is first and foremost an outstanding medical school which is held in high esteem internationally. It is well-renowned for its medical research and practice and its international reputation transcends the small size of Austria as a country. Numerous scientists such as Ignaz Semmelweis, Karl Landsteiner, Sigmund Freud and Konrad Lorenz gained international recognition for their significant contributions to the field of medicine.

Innsbruck therefore combines for students the spirit of a young city dominated by students and situated in the midst of famous skiing resorts with the heritage of a great tradition and the professional environment of a high ranking institution for education and training.

Today Austria has four medical universities: public universities at Vienna, Graz and Innsbruck and the private Paracelsus University at Salzburg.

As in most other countries, it is not easy to get into medical school as the number of applicants far exceeds the number of available places. Medical Universities have therefore adopted various admission procedures. In Vienna and Innsbruck, applicants take a general admissions test, the 'Eignungstest fuer das Medizinstudi- um' (EMS) (ability test for medical education), which tests skills and competencies like stereoscopic vision, concentration, knowledge of maths and the ability to understand scientific texts. The test is designed to be very exhausting and stressful. The tension is palpable when one enters the large examination hall where approximately 1800 applicants are gathered to compete for a mere 400 places at the medical school. During the test the level of pressure rises because the test is designed to be too long to complete in the short time allowed. Accordingly, there is a strong sense of discouragement among students after the test. Six weeks after the test, the results are published together with the list of the 400 candidates that are invited to start their studies in the upcoming semester.

From the very start the curriculum is quite challenging. To help students cope with their new situation they are guided during the first four weeks before the first exam by senior more experienced students acting as tutors.

The basic structure of the curricula of the three public medical universities in Austria is similar. The curriculum is divided into three parts: 'pre-clinical', 'middleclinical' and 'clinical', consisting of modules, such as 'musculoskeletal system' or 'components of life'.

Despite the basic similarity, the curricula differ significantly because medical schools are free to design their own programme and determine their own concept and standards of academic excellence. 
Unfortunately, these differences are a barrier to students moving between universities and most students complete their studies at one medical school.

However, in order to offer students international experience, there are many scholarships enabling students to work in hospitals abroad during semester breaks.

The medical programme at Innsbruck Medical University comprises twelve semesters. From the first year to the tenth semester, students have to take an exam consisting of 800 multiple choice questions every second semester.

It is therefore important that these questions test students' basic medical knowledge. However, as teachers are required to produce new questions for the same topics every year, in practice questions tend to ask about details that may be overly specific and not adequately reflect basic medical knowledge. This system has come under strong criticism from both students and teachers.

Innsbruck has a long and established history in medical education and it is the seat of one of the oldest faculties of anatomy in Europe. Unlike other medical schools where students often do not have sufficient access to practical courses in anatomy, Innsbruck Medical University upholds its longstanding tradition of intensive dissection courses in the first two years. Groups of eight students are provided with one human body for anatomical observation and medical procedures. This offers students extensive practice in gross anatomy and gives them ample opportunity to develop their anatomical skills and knowledge.

The 11th and 12th semesters are designed as clinical clerkships ('KlinischPraktisches Jahr') in six disciplines. During this year students can also gain international experience. Because this practical year was only established fairly recently with the introduction of a new curriculum, there was no previous experience with this type of training and there has not been enough time for improvement. An important benefit of the new curriculum is the reduction in the size of student groups to maximize their work experience and enhance their learning.

Medical studies in Austria are a diploma study, which means that students have to write a diploma thesis to complete their studies. Strangely, this diploma thesis is the basis for the title of Medicinae Universalis Doctor (Dr. med. univ., Doctor of Medicine). However, it is not equivalent to a PhD degree. Consequently, students additionally have to earn a $\mathrm{PhD}$ degree in order to obtain a postgraduate lecture qualification.

After completing undergraduate medical studies students in Austria have to work as a 'Turnusarzt' in different medical disciplines for a minimum period of 36 months. Having successfully completed this period, graduates are awarded the ius practicandi (licence to practice). The 'Turnusarzt' system is subject to strong criticism because it is considered too time consuming and to delay specialty training until very late in a trainee's development. As a consequence, plans are in the offing to change this system fundamentally, or at least to shorten the required 36 months of working as a 'Turnusarzt'.

Another issue that should be mentioned is the relationship between German and Austrian students at Innsbruck. The population of Germany is ten times the size of the Austrian population and approximately $20 \%$ of medical students in Austria are from Germany. In Innsbruck, which is located just $30 \mathrm{~km}$ from the German bor- 
der, this percentage is even higher. Unable to secure a place at a German medical school because of the "numerus clausus" (limited admission), many young Germans try to gain entrance to an Austrian Medical University by participating in the EMS test. This situation has aroused much heated debate in Austria. Presently, Austria is attempting to control the number of German students by allocating a maximum number places for foreign students from countries within the European Union. According to current regulations, at least $75 \%$ of students have to be Austrian citizens.

Overall there are several advantages to studying medicine at Innsbruck Medical University. From the first semester onwards, students benefit from a good education in clinical practical subjects. As early as the first weeks of the first semester students can take part in clinical training in the hospital where they can join nurses and doctors. Moreover, there are lectures by general practitioners in addition to lectures by professors specialized in anatomy or biochemistry. This enhances learning, since students are brought into contact with "real medical practice" from the very beginning of their training. The strong clinical orientation is the main reason for the good reputation that medical students from Innsbruck have in numerous hospitals across Europe. Many of our students undertaking clinical traineeships elsewhere have been complimented by doctors on the standard of their clinical knowledge, which even in the early semesters is very high compared to that of medical students from other universities.
The early clinical orientation makes it easy for students to stay highly motivated even during the preclinical phase. Obviously, there are also theoretical lectures but students additionally gain more indepth experience by practical training in small student groups.

Another important aspect is that students are involved in almost every decision of the university concerning their education and take an important and proactive role in improving the curriculum.

The experience we have gained over the last seven semesters has convinced us that education at Innsbruck Medical University is highly competitive. Looking back we have not once regretted our decision to study at Innsbruck and we can definitely recommend it to all those considering Innsbruck Medical University for their medical studies.

\section{The authors:}

Ursula Neubauer, 3th year student in medicine, University of Innsbruck.

Gregor Kastl. 3th year student in medicine, University of Innsbruck.

Correspondence

Ursula Neubauer, Michael-Gaismair strasse 11, 6020 Innsbruck.

E-mail:ursula.neubauer@student.i-med.ac.at. 